\title{
A Flood Risk Assessment based on an OpenStreetMap Application: A case study in Manmunai North Divisional Secretariat of Batticaloa, Sri Lanka
}

\author{
S. Suthakaran*1, A. Withanage ${ }^{2}$, M. Gunawardhane ${ }^{3}$, J. Gunatilake ${ }^{4}$ \\ ${ }^{1}$ The World Bank, Colombo 03, 00300, Sri Lanka \\ ${ }^{2}$ Department of Medicine, Faculty of Medicine, University of Kelaniya, Ragama, 11010, Sri Lanka \\ ${ }^{3}$ Postgraduate Institute of Science, University of Peradeniya, Peradeniya, 20400, Sri Lanka \\ ${ }^{4}$ Department of Geology, Faculty of Science, University of Peradeniya, 20400, Sri Lanka
}

\begin{abstract}
In the recent past, Sri Lanka has been experiencing an increase of intensity and frequency of natural disasters. Therefore, the study was carried out to introduce an Open Source application to collect the field level information and to identify the flood inundation areas through a 3D model. The case study area included 48 Grama Niladhari Divisions in Manmunai North Divisional Secretariat (DS), Batticaloa District, Sri Lanka. The study helped to analyze the role of OpenStreetMap (OSM) to support the mapping of the flood risk level of the study area. This objective was achieved by collecting flood exposure data through community participatory method using OSM, which was integrated into a Digital Elevation Model (DEM). Elevation points were collected using Google Earth and TCX Converter. The flood hazard maps were created using inputs such as water depth and flood extent of the DEM and verified through a local community participatory mapping exercise. Next, vulnerability maps were generated based on factors such as building characteristics of houses, population of the areas and the availability of assistance during the flood scenarios in 2010 and 2011. Finally, the flood risk map of the study area was prepared in combination with hazard and vulnerability maps. The study produced a user-friendly application of open source and GIS to develop a 3D flood risk model for the identification of flood risk levels. Exposure data have been uploaded into the OSM, therefore, it can be accessed anytime, anywhere and by anyone. The extent of study area is 2593 ha; where about 25,000 families live and there are more than 32,000 buildings. The building footprint database was established using JavaOSM and Bing satellite imagery. It was updated with the building attributes produced by the data collection exercise. This study showed that when the water level increases in the lagoon, nearly 25 GN Divisions (GNDs) out of 48 GNDs are under high flood risk. The developed online geospatial database in OpenStreetMap is an important asset, since it supports the preparation of an emergency flood risk management plan, which helps to accelerate the emergency response and flood mitigation plan for the study area.
\end{abstract}

Keywords: Flood Risk Assessment, Community Participatory Mapping, OpenStreetMap, Sri Lanka

\section{Introduction}

Batticaloa District is located in the Eastern coast of Sri Lanka on a flat coastal plain bounded by the Bay of Bengal. The district accounts for $3.8 \%$ of the country's total land area (approximately 2,633 $\mathrm{km}^{2}$ ) and with an elevation between $1.20 \mathrm{~m}-15.0 \mathrm{~m}$ above Mean Sea Level. The coastal undulating plain is between $5 \mathrm{~m}$ and $50 \mathrm{~m}$. The coastal uplands area is situated above $50 \mathrm{~m}$.

Flood is the most impacting type of natural disasters world-wide and is expected to cause increasing damages in the near future. The effective assessment of flood hazard requires community participation, because the communities are the first responders in case of a disaster. It also requires the use of new or 
recently-adopted technology with information and parameters modified to the local context, resources and other needs.

Therefore, the new terminology of Community-based Disaster Risk Reduction (CBDRR) was coined to help communities in an organized way. The risk assessment should become the product of dialogue and negotiation between different actors with their perceptions. The use of adequate methods and skills that support what has been called community involvement and empowerment has been explored by many disaster risk researchers.

Currently, in Sri Lanka, local maps are not sufficient to create detailed emergency management plans and mitigation plans to aimed to reduce the loss of properties and lives when a disaster occurs. Therefore, there is a timely requirement of building a series of detailed maps across the country utilizing opensource software such as OpenStreetMap (OSM) to help emergency responders and planners in the future.

This method of disaster risk reduction is now practiced by the World Bank in South Asian Region through 'Open Cities project' which helps to prepare emergency preparedness towards natural disasters and managing crisis. The OpenStreetMap platform has been developed to bring the power of community mapping to support urban planning and disaster management investments.

Therefore, the present study was carried out as a case study, to explore the possibility of assessing flood risk and resilience in the coastal areas of Eastern Province of Sri Lanka through Community-based Participatory Approach and OSM technologies.

\subsection{Problem statement}

Batticaloa Town is in Manmunai North (MN) Divisional Secretariate (DS) Division, surrounded by Batticaloa lagoon. During the rainy season, all the natural drainages and streams begin to flow and end up in the lagoon as a result, lagoon water level rapidly increases.

Sri Lanka is at the risk for numerous types of extreme events such as, the 2004 tsunami, one of the deadliest disasters in human history, killed over 30,000 people and left over 5000 missing in Sri Lanka (Nishikiori et al., 2006). According to the Bureau for Crisis Prevention and Recovery in 2004 report, the average annual flood exposure in proportion to the population, Sri Lanka was ranked $11^{\text {th }}$ in the world. The vulnerability to flooding is increasing due to climatic changes, population growth and urban development in flood-prone areas (Barredo, 2009), (Abenayake et al., 2018).

MN DS Division is a multi hazard prone area which is located close to the lagoon and the sea. Most of the Grama Niladhari (GN) Divisions in the study areas were affected by the Tsunami in 2004. This makes flood risk management an important responsibility for governments and municipalities. In this context, number of Non-Governmental Organizations and Government Agencies have been implmenting Disaster Risk Reduction (DRR) program in the areas. However, there is no emergency response plan if the heavy floods happens in the areas.

Therefore, this case study intends to introduce an Open Source application to collect the field level information and to identify flood inundation areas through a 3D model.

This study will explore the possibility of assessing flood risk and resilience in the coastal areas of Eastern Province of Sri Lanka, by analysing a pilot DS Division (MN) in the Batticaloa District, which was affected by Tsunami in 2004.

The first part of the study is focused on the use of Community-based Participatory Approach to introduce a disaster exposure data collection method to find the building characteristics. It assesses the disaster exposure of the individual buildings in the study area through a flood risk assessment method using Open Street Map and Geographic Information System (GIS). Secondly, the study will identify the elevation pattern; and create a 3D model; and verifies the flood risk areas using results from a community participatory mapping exercise.

\section{Literature review}

The first step in an effective disaster management is the identification and profiling of hazards (Smith, 2001). Hazards are generally classified as of natural, technological and human origin. To cope with these threats, the United Nations General Assembly adopted a global program in December 1989 to reduce the losses caused by natural hazards and proclaimed the $1990 \mathrm{~s}$ as the International 
Decade for Natural Disaster Reduction (IDNDR).

Flood risk management is a subcategory of Disaster Risk Management (DRM). The purpose of the risk assessment is to establish a standard and comparable measure of the probability and consequences of the identified hazard in order to lessen the impacts of natural hazards (UNISDR, 2009).

In the past few decades, prevention and preparedness phases in DRM use ways to reduce the vulnerability of communities by strengthening their capacity to develop coping strategies were emerged (Birkmann, 2006). Numerous studies have addressed the contemporary vulnerability of different communities in the world to flooding from the point of view of the natural hazards of understanding exposure, the number of people and structures affected (Roy et al., 2001; Nirupama and Simonovic, 2007).

To promote sustainable development and minimize the effects of floods, it is essential to use spatial data and technologies because both hazards and vulnerable societies are changing in space and time. The development and use of spatial analysis for Flood DRM, is increasingly important, for several reasons (Newman et al., 2017). These include natural hazards are having a significant impact on communities and economies, losses due to natural disasters are expected to increase in the future due to increasing urban areas, consequently increasing exposure and vulnerability (Neumayer and Barthel, 2011; Daniell et al., $2016 \mathrm{~b})$. This is aggravated by cities often developed adjacent to rivers and oceans (McGranahan et al., 2007).

The total economic losses from natural hazards over the period between 1900-2015, approximately $40 \%$ were due to flooding (Daniell et al., 2016b). Further, risk reduction which is broadly recognised as being more cost effective than response and recovery (Rose et al., 2007). For example, Harper et al. (2013) investigated flood risk-reduction projects in Australia and found that benefit cost ratio was more than 1 and up to 9, where risk-reduction investments were made that targeted high-risk locations with appropriate strategies.

Knowledge of the local community has been considered as an important primary source of information related to flood risk assessment.
These data can be utilized for the estimation of the risk and for the complete deviation of the frequency of the floods, the characteristics of the floods, the triggers and their consequences. Information on water propagation, duration and maximum water level can be obtained using local knowledge and participatory GIS (Craig et al., 2002).

OSM is an open-source and open-access project founded in 2004 by Steve Coast. OSM project's hub contains four parts. There is a Google Maps style online mapping interface, which lets visitors can discover geographical areas. Users can use export function to download OSM information for further use or processing. The editing tab allows anyone to contribute to the project by digitizing, uploading GPX, or correcting errors in their local areas. The OSM community wiki, contains information about the project and offers guidance. This study utilized the Java OpenStreetMap Editor (JOSM). It offers advanced functionalities such as linking OSM features to photos and audio notes, support data conflict resolutions.

Schelhorn et al. in 2014 studied and results showed that the identification of elements at flood risk from OpenStreetMap is a suitable and cost-effective alternative for supporting local governments and communities in risk assessment and emergency planning. OSM collaborative maps can be used as a potential source of Volunteered Geographic Information (VGI) for identifying elements at risk of a community including disaster management (Neis et al., 2010; Schelhorn et al., 2014 and Soden et al., 2014). By 2018, the OSM project had almost 4.7 million users who contributed almost 6.2 billion GPS points and 514 million lines, which are partially based on 4.6 billion notes and 5.9 million relations that have been uploaded (OSM stats, 2018).

Pasi et al. (2015) studied the application of OSM, who have chosen to use free open source tools such as OSM, JOSM and GPS essentials with Field papers. Information to disaster risk management in the novel scope of risk assessment. Pasi et al. (2015) had compared flood risk assessment profiles produced using data collected by OSM against official geodata produced by local governments in two cities of Veneto, Italy. They found that OSM data present several advantages and have a great potential for improvement, suggesting that 
OSM should be integrated in future risk assessment processes.

Very few literatures are available for local knowledge compiled for flood risk and risk assessment (Elwood, 2006). OSM is utilized to find the flood inundation areas, flood risk mapping, vulnerability mapping and risk assessment using participatory mapping and Participatory Geographic Information Systems (PGIS).

Disaster exposure data is an essential when Disaster Management Centre of Sri Lanka deals with pre- and post-disaster events. But in the Sri Lanka context, it is very challenging because Sri Lanka doesn't have such data which is a key gap in Sri Lanka. However, Disaster Management Centre has implemented two main projects in collaboration with World Bank Sri Lanka to collect the exposure information of the buildings in Batticaloa and Gampaha Districts which could meet the future demand on exposure information for other areas. In Sri Lanka, government and academic volunteers mapped over 30,000 buildings and $450 \mathrm{~km}$ of roadways using OSM (GFDDR, 2018).

Recently Disaster Management Centre in Sri Lanka has launched a disaster risk information platform, which is very important initiative for researchers, DRR practitioners, public, departments and academic institutions to extract the information freely. In this study, collection of the exposure information and data sharing method through Open Street Map application are applied.

\section{Method and materials}

This study also utilized the free and open source software to collect the exposure data on the buildings and extracted elevation point from Google Earth to identify the flood inundation area. This research utilized the qualitative and quantitative methods to collect the field level information to measure the flood level, vulnerability level and risk level of the study area.

\subsection{Data collection}

Flow diagram of the data collection and entering methodology is shown in Figure 1. The OSM was utilized as a platform to build a database of survey data for the Exposure
Mapping Activities in the Manmunai North DS Division.

A Community-Based Participatory Approach was adopted by the National Housing Development Authority, Municipal Council of Batticaloa and the community for the exposure data collection method to find the building characteristics.

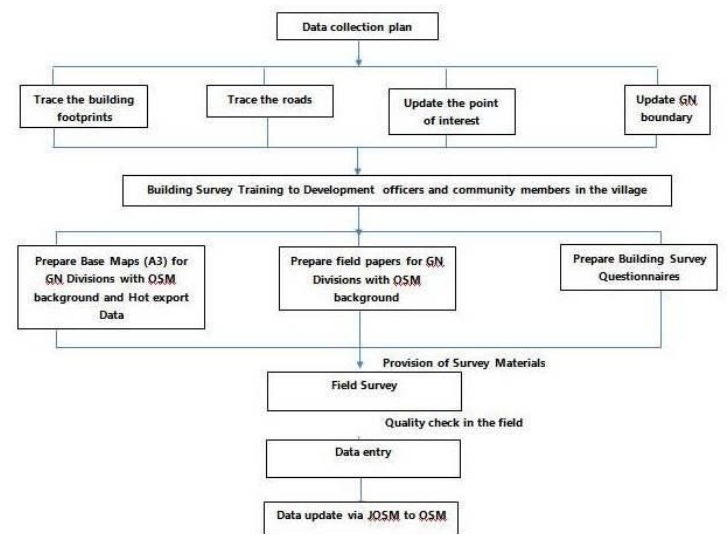

Figure 1: Flow chart for data collection and entering methodology to use the OSM

48 Enumerators (University Graduates from MN Divisional Secretariat) were provided by MN Divisional Secretariat for data collection. They were trained to read the maps, to find landmarks in the field papers, locating them accurately on the field and to compare buildings on the field paper with ground situation. All enumerators were divided into 5 groups for data collection based on geography of the study area. Base maps, field papers and questionnaires were utilized as survey materials.

Staffs from Batticaloa District Secretariat and Municipal Council entered the building data. Bing satellite image which offered on JOSM was utilized create a preset (XML file) to upload all the information in a single interface and it was comprised of the questionnaire in digital form.

JOSM, QGIS and Tasking Manager were utilized as digitizing tools. Digitizing activity divided into four tasks for the convenience such as tracing the building footprints using JOSM, tracing the roads, updating the point of interests and updating the GN Boundaries. During this process a number of new roads were traced and named.

Secondary data such as the district disaster management plan, comprehensive land use plan, statistical profile of the district (2015), 
committee and village disaster plan and relevant maps from LUPPD were collected. World Bank supported financially and technically to carry out the exposure mapping exercise.

\subsection{Data scrubbing}

Data scrubbing was the process of correcting the errors in the OSM database which could be cautilized by mistake during the data entry process. The process of data scrubbing includes :

a) Data ripped off from the OSM server using 'PostgreSQL': Using PostgreSQL as a tool to download the updated data from the OSM server as shape files.

b) Using QGIS, attributes of the OSM data filtered: Downloaded data from OSM servers opened via QGIS, and filtered through attribute tables to get to know the fields that contain 'null' value

c) Compression between JOSM and QGIS: The filter results that contains 'null' value have been re-updated based on the data on questionnaire and re-checked survey results.

\subsection{Community participatory mapping exercise and focus group discussion}

The process of identifying, collecting previous flood records, community's knowledge and perception about flooding was made through the intensive use of several participatory tools such as in depth interviews, focus group discussion and transect walk. The main theme included:

a) Flood events experienced in terms of type, magnitude, duration and date.

b) Outcome of flood scenario by considering physical, economic and social aspect of the family.

c) Mapping exercise developed to manage flood risk

d) Use of resources available at DS level

e) Influence of flood related issues in their life style

Elevation point data were collected through the Google Earth Pro and (Base on SRTM data) converted into $\mathrm{kml}$ file. The elevation point is utilized with the 3D analysis tool to create Digital Elevation Model (DEM).

\subsection{Flood hazard, vulnerability and risk mapping}

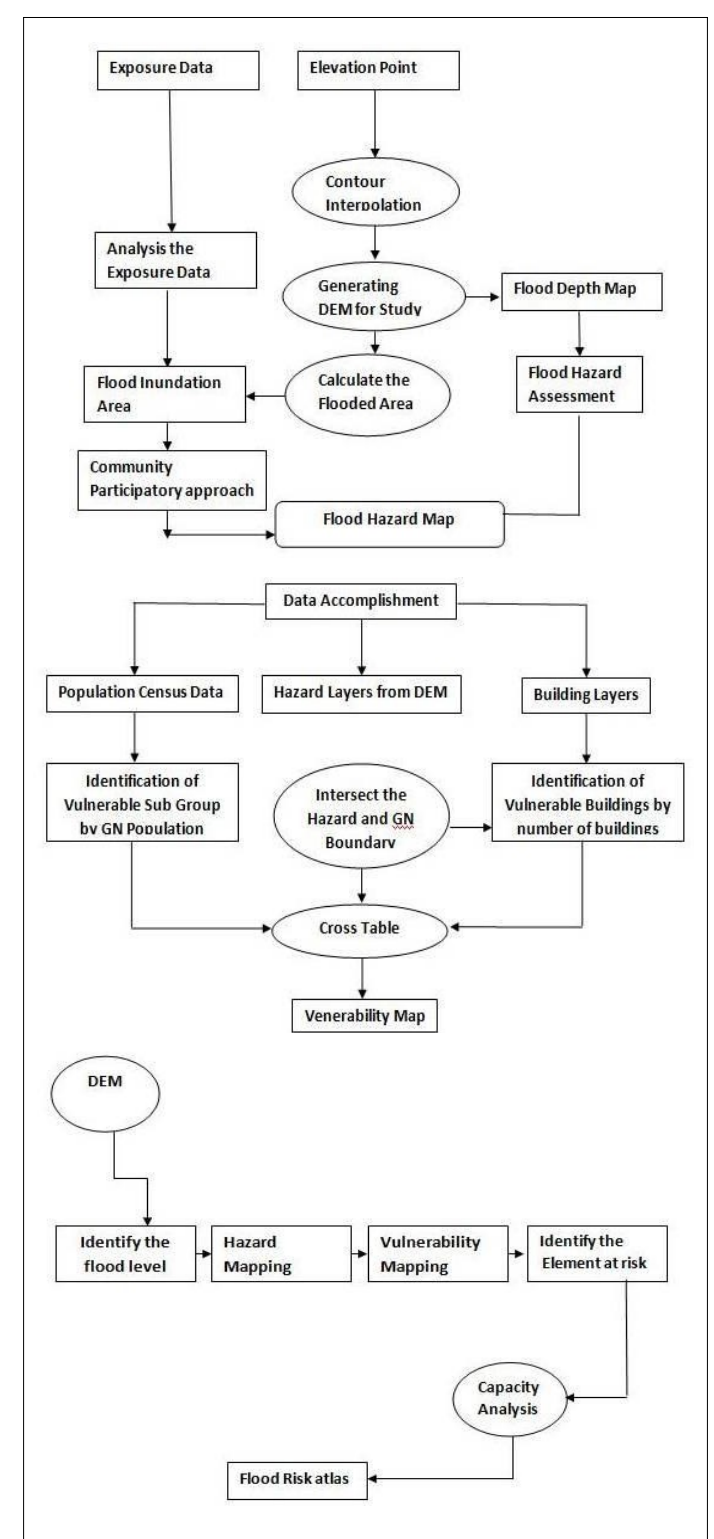

Figure 2: The flow chart of the hazard, vulnerability and risk mapping

The mapping of the extent of the flood based on community participatory approaches with GIS analysis was done. The perceived perception of the hazard through a participatory focus group discussion and the DEM approach analysis were converted into risk categories that were then applied to the special results of distribution, depth and duration of the floods.

Flood hazard maps were classified according to flood inundation areas based on the depth of floods and elevation (categories: 
0-2 $\mathrm{m}$ high hazard, 2-4 m moderate hazard and 4-6 m Low Hazard). The flood-prone portion of the village has been artificially surrounded by human interventions, such as settlements and fishing activities.

The characteristics of buildings, number of buildings by GN boundary was utilized to integrate with the population and flood inundation areas to identify the vulnerability of the areas.

In this approach, flood risk map was prepared in combination with the vulnerability of the flood, hazard level, identified elements at risk and capacity of the DRR team in the study area. The results of the risk maps helped to determine the area's most prone to flooding and where communities cannot cope with the disturbances cautilized by the floods.

\section{Results and findings}

The OSM and participatory data collection methods were combined with GIS. This is a useful approach to improve the understanding of floods as a dynamic hazard for communities in the study area. The integration of local knowledge in GIS-based methods could help to interpret different aspects of flood risk. In addition, it has expanded the understanding of how floods become a threat faced by residents of these exiting settlements and local villages in their daily lives.
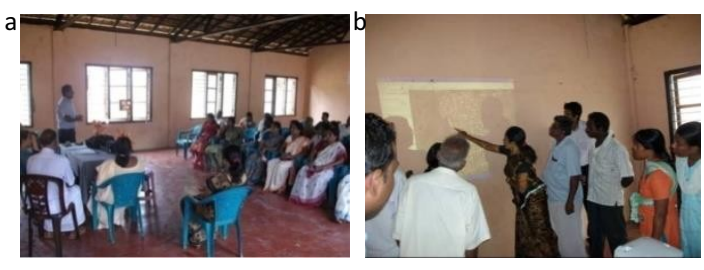

Figure 3: (a) integration of local knowledge; (b) community mapping

\subsection{Flood inundations areas}

The inundation areas for flood with the assumption that the water level increased by 2 m interval (0-2 High Hazard, 2-4 m, Moderate Hazard and 4 -6 m Low Hazard) in the Lagoon.

The study showed that there is a flood hazard in the area when the water level increased in the lagoon. Figure 4 shows the flood hazard level and details of flood inundation building. Table 1 shows that number of buildings faces the possible flood hazard based on the flood hazard,. According to the building survey, five percent of buildings are built up in the high flood hazard area and $16 \%$ of buildings are built up in the moderate flood hazard area.
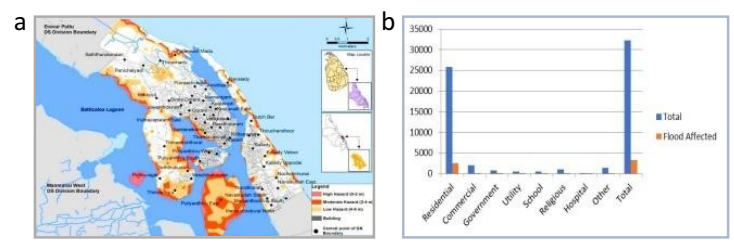

Figure 4: (a) hazard map; (b) flood inundation building

Table 1: Number of buildings facing the possible flood threat

\begin{tabular}{|l|c|c|c|}
\hline $\begin{array}{l}\text { Building } \\
\text { Usages }\end{array}$ & High & Moderate & Low \\
\hline Residential & 91 & 392 & 2021 \\
\hline Commercial & 16 & 26 & 149 \\
\hline Government & 5 & 27 & 108 \\
\hline Utility & 7 & 18 & 64 \\
\hline School & 2 & 6 & 9 \\
\hline Religious & 3 & 22 & 93 \\
\hline Hospital & 0 & 8 & 11 \\
\hline Other & 50 & 28 & 119 \\
\hline Total & 174 & 527 & 2574 \\
\hline
\end{tabular}

\subsection{Vulnerability level of the study area}

Vulnerability level was identified based on the flood hazard level and the building exposure information. Multidisciplinary families, income- generating families and fishing families are found to be living in the vulnerable areas.

\subsection{Risk level of the study area}

Flood risk assessment identified that 25 GNs are under high flood risk zone. The indicators were utilized to find the vulnerability and the risk of the areas. Figure 5 shows results of vulnerability and risk maps of the study area.

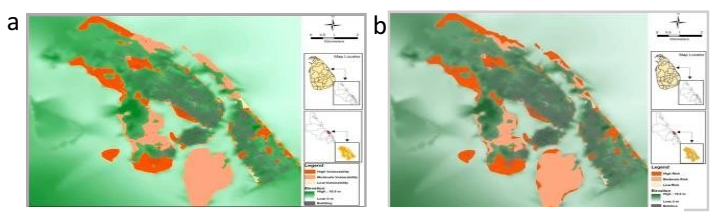

Figure 5: (a) vulnerability map; (b) risk map

\subsection{Developed online geospatial web base system}

Spatial data are very important to multidisciplinary decision making analysis 
especially for post disaster and pre disaster activities. This study developed online geospatial database which can be used by anyone. Spatial data sets can be obtained from the Open Street Map application.

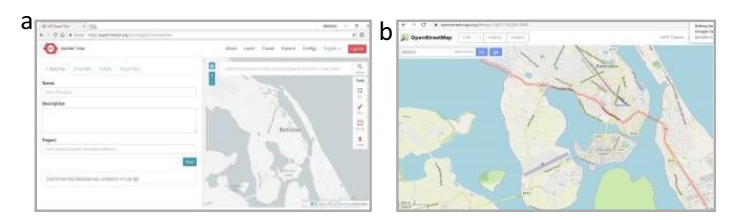

Figure 5: (a) hot export tool; (b) openstreetmap

\section{Conclusion and Recommendations}

MN is an urban area, with a built-up areas in the flood risk zones and these factors favor flooding, however, non- governmental and government organizations have not seriously considered that these areas are located in the flood prone during previous floods. Therefore, results of this vulnerability assessment propose a set of recommendations to gain attention by the different organizations working in DRR activities.

This article discusses the importance and possibility of assessing flood risk and resilience in the coastal areas of Eastern Province of Sri Lanka trough community-based participatory approach and OSM technologies.

Through community participatory flood risk assessment, mitigation measures have been addressed to reduce the risk level for the study area. Several mitigations measures in the newly construction of residential and public buildings need to be considered with the plinth level above $2 \mathrm{~m}$ from surface especially in the high flood prone area and also renovation of drainages.

The study developed the road networks for the areas with the details of road name and the surface condition which can be utilized to prepare evacuation route with the concern of flood risk assessment. The study has identified and located public buildings and the safe area for MN DS Division which can help to find the evacuation location to accommodate people when the disaster happens. These results can be utilized by the decision makers in the area.
Online geospatial database is available to use everyone and can be updated by OSM users who are interested. In future, District Secretariat and Disaster Management Centre can utilize this online data base to prepare a DS Division Development Plan and devise a monitoring mechanism.

The establishment of flood prone areas is essential, since areas with high flood risk and areas of vulnerability have been identified in DS. These areas should be protected as ecologically sensitive areas surrounded by lagoons. Common buildings such as the electricity board, fire theaters, hospitals, schools and community-based buildings should not be built in flood-prone areas. Many vulnerable buildings are found in areas prone to flooding. The competent authorities should introduce new techniques to build flood protection buildings.

The Disaster Management Center of the Batticaloa District must be aware of the preparation of an Emergency Management Plan, an Evacuation Route, an Evacuation Center and a Cam Management Plan that can help to reduce impact of the flood. Community awareness is very important for these areas, as the community is well informed about periodic floods, but not major floods.

The District Secretariat and the Batticaloa Disaster Management Center need to work closely with the Department of Meteorology and the Department of Irrigation and prepare an appropriate precipitation prediction system for upper catchment. The information management system is not well established in the district, the district secretariat needs the help of the Open Street Map application to extract the information and generate an emergency management plan, a response, a contingency plan and mitigation taking into account with the concern of relevant field experts.

\section{Acknowledgements}

Authors wish to thank the administrators of the District of Batticaloa, involved their participants of the study for their support and participation. The World Bank of Sri Lanka funded to initiate participatory mapping. 


\section{References}

Abenayake, C. C., Mikami, Y., Matsuda, Y., \& Jayasinghe, A. (2018). Ecosystem services-based composite indicator for assessing community resilience to floods. Environmental development, 27, 34-46. https://doi.org/10.1016/j.envdev.2018.08.002

Barredo, J. I. (2009) Normalised flood losses in Europe: 1970-2006. Natural Hazards and Earth System Sciences, 9(1), 97-104. https://doi.org/10.5194/nhess-9-97-2009

Birkmann, J. (2006) Measuring vulnerability to promote disaster-resilient societies, conceptual frameworks and definitions, Routledge, London.

Craig, W. J., Harris, T. M., and Weiner, D. (2002) Community participation and geographic information systems. Community Participation and Geographical Information Systems (pp. 29-42). CRC Press. https://doi.org/10.1201/9780203469484

Daniell, J., Wenzel, F., and Schaefer, A. (2016) The economic costs of natural disasters globally from 1900-2015: historical andnormalised floods, storms, earthquakes, volcanoes, bushfires, drought and other disasters. EGU General Assembly Conference Abstracts (Vol. 18, p. 1899).

GFDDR (2018) New-Field-Guide-Explores-Open-Data-Innovations-Disaster-Risk-AndResilience. Available from https://www.gfdrr.org/en/feature-story/new-field-guide-exploresopen-data- innovations-disaster-risk-and-resilience. Accessed on 2018/12/07.

Nation's Resilience to Natural Disasters. Deloitte Access Economics and Australian Business Roundtable for Disaster Resilience and Safer Communities, Kingston, ACT, Australia.

McGranahan, G., Balk, D., and Anderson, B. (2007) The rising tide: assessing the risks of climate change and human settlements in low elevation coastal zones. Environment and urbanization, 19(1), 17-37. https://doi.org/10.1177/0956247807076960

Neumayer, E., and Barthel, F. (2011) Normalizing economic loss from natural disasters: a global analysis. Global Environmental Change, 21(1), 13-24.

https://doi.org/10.1016/j.gloenvcha.2010.10.004

Newman, R., Ashley, R., Molyneux-Hodgson, S., and Cashman, A. (2011) Managing water as a socio-technical system: the shift from 'experts' to 'alliances'. In Proceedings of the Institution of Civil Engineers-Engineering Sustainability (Vol. 164, No. 1, pp. 95-102). Thomas Telford Ltd. https://doi.org/10.1680/ensu.1000032

Nirupama, N. and Simonovic, S. P. (2007) Increase of flood risk due to urbanisation: a Canadian example. Natural Hazards, 40(1), p.25. https://doi.org/10.1007/s11069-006-0003-0

Nishikiori, N., Abe, T., Costa, D. G., Dharmaratne, S. D., Kunii, O., and Moji, K. (2006) Who died as a result of the tsunami?-Risk factors of mortality among internally displaced persons in Sri Lanka: a retrospective cohort analysis. BMC public health, 6(1), 73. https://doi.org/10.1186/1471-2458-6-73

OSM Stats (2018) Available from https://osmstats.neis-one.org/?item=members. Accessed on $2018 / 08 / 12$. 